\title{
Forecasting the effectiveness and economic security of organizations, branches of the national economy
}

\author{
Valeriya Krolivetskaya ${ }^{1 *}$, and Eduard Krolivetsky $^{2}$ \\ ${ }^{1}$ St. Petersburg State Economic University, Department of Banks, financial markets and insurance \\ 19006821 Sadovaya st., St. Petersburg, Russia \\ ${ }^{2}$ St. Petersburg State Institute of Cinema and Television, Department of Management of Economic \\ and Social Processes in the Cinema and TV Industries, 19820513 Pravdi st., St. Petersburg, Russia
}

\begin{abstract}
The article reveals the essence and functional purpose of forecasting economic and social results, efficiency, economic security of organizations and sectoral components of the national economy, the relationship of the main economic characteristics and economic security, justifies the feasibility of using economic and mathematical methods of forecasting to ensure economic security, accuracy and significance of forecast estimates. The article reveals the composition of generalizing indicators of correlation characterizing for the medium and long-term development of sectoral and local components. Also it reveals a set of measures and actions to collect and systematize socio-economic information about the current and retrospective activity of the object of planning and forecasting which would ensure the adequacy of forecasting of the normative and threshold values of economic security, interaction with other technological elements of the management system of medium and longterm development of business entities, economic activities (sectoral components) of the services sector.
\end{abstract}

\section{Introduction}

Use Forecasting of social and economic results, of the resources' effectiveness used by the local and sectoral components of the national economy in the process of establishing and ensuring the adequacy of their assessments of economic security in the medium term is one of the most effective tools to improve the accuracy and significance of the planned benchmarks of efficiency and sustainable development.

The forecast values of economic, social results, efficiency of the organization's resources used, as in industry as well in services sectors of the economy are quantitative and qualitative characteristics of the trends of retrospective socio-economic development and ensuring adequate economic security of these objects [1].

Forecasting the level of economic security in the process of determining trends in the socio-economic development of an organization, the industry at the end of the relevant year

* Corresponding author: mail26@yandex.ru 
is based on analyzing and taking into account the state of its resource potential, changing under the influence of economic and innovative unstable states of the external business environment, demand for services, pricing, marketing performance measures to promote products and services to the market [2].

\section{Applied methodology, research materials}

A qualitative study was carried out, the main presupposition for which the authors consider the opportunity to analyze and identify the immanent features of the process of forecasting economic results and efficiency of business entities. In order to analyze the object of forecasting the medium-term estimates are obtained by economic and mathematical methods with a representative sample (dynamic economic indicators), as well as expert methods with no data on the retrospective economic activity. These are necessary to establish medium-term quantitative assessments of the economic results and the efficiency of the used resource potential, in confidence intervals and threshold values of economic security perspective period.

The established confidence intervals for the indicators of economic results, the efficiency of the resources used, as characteristics of the sustainability of the state of economic security of the management object, are the limitations of their achievement, which take into account the most probable deviations from the predicted estimates, expressed by the coefficient of approximation, depending on the changed trends of economic and innovative development under the influence negative factors of external and internal environments.

The paper considers the research methodology in the whole.

\subsection{The influence of the accuracy and significance of forecasting estimates on socio-economic development}

The points of view of a number of economists on the feasibility of determining in the medium and long-term periods of socio-economic development of business entities, branches of the national economy of the main performance characteristics that are in close correlation with economic security through expert extrapolation of retrospective activities based on adherence to the principle of economic growth the effectiveness of the resources used from the previously achieved level, in our opinion, cannot to be acceptable neither economically nor adequately to the established target orientation for achieving the maximum possible values of economic indicators. This is due to the fact that in conditions of significant changes in the state of the external environment in the medium term, compliance with the trends of growth of economic results and production efficiency does not allow to establish on an adequate basis the level of the planned economic security according to the set of economic indicators. In turn, this may lead to a complete loss of the properties and significance of the functions of forecasting and long-term planning.

In this regard, it should be noted that the definition of adequate medium-term forecast values of economic results and resource consumption costs for business entities and sectoral components of the national economy is the acceptable quantitative guideline for establishing the dynamics of their development effectiveness and economic security, to achieve which in the medium term, subject to the economic and innovative influences of factors of unstable external and internal environments.

Satisfaction of the target orientation of the subject of forecasting and socio-economic development planning towards achieving a mid-term assessment of the economic result, the effectiveness of the resources used, compliance with the level of economic security, in our opinion, is possible in the planning system, in which the economic indicator turns into a 
benchmark for achieving or upcoming economic and innovative changes in the state of the external business environment [3].

Estimates of forecasting, as characteristics of changes in the sustainability of the level of economic security, management functions of the current and future socio-economic development of business entities, sectors of the economy, their functional purpose express through the ability to extrapolate quantitatively and qualitatively the transfer of changes in the dynamics of retrospective activity for a specified period of time based on the normative significance and adequacy of the forecast estimates reaches the planned parameters of economic security, the results and the effectiveness of the resources used.

It should be noted that forecasting retains its functional properties both for long-term planning and for determining the level of economic security, regardless of the conditions and degree of influence of negative factors of the macro-, meso-, microenvironment on the dynamics of changes in economic indicators of organizations and sectors of the national economy.

In the economic literature, the most common point of view of interpreting the concept of "forecasting" is the one in which forecasting is presented as the initial preparatory stage of ensuring the adequacy and importance of planning the socio-economic development of a business entity, industry, or national economy.

The property of forecasting, as a tool to ensure an economically acceptable level of accuracy of the efficiency of the socio-economic system, its economic security in the medium and long term, is justified by the authors from the standpoint of the dominant role of the planning function in relation to forecasting, in accordance with which the forecast characteristics economic, social results, the effectiveness of the resources used are indicative and only preliminary $[1,5]$.

In the above definition of forecasting properties, the main role of this function in the process of determining deviations from the normatively established level of economic security, the performance of the local or industry component is the property of transferring the dynamics of economic changes in the retrospective period to the medium and long-term forecasting.

However, endowing the forecasting function with only one of its functional purpose properties, in our opinion, cannot be a preliminary assessment of the achievement of the greatest economic, social results, efficiency, level of sustainability of economic security in conditions of unchanged economic and innovative state of external and economic internal environments This statement is based on the fact that the functional purpose of forecasting is not only the determination of the adequacy of the balance of available resources to the achievement of economic, social results, the effectiveness of the resources used, but also interaction with other management functions, as well as the definition of meaningful, statistically acceptable security activities of organizations and sectoral components of the national economy.

The medium and long-term indicators of the projected level of economic security of sectoral and local components of the national economy, in accordance with the implemented State Strategy of Economic Security, are such a composition that adequately characterizes the ability of the national economy, its structural components in the current and future periods:

1. Carry out activities in the mode of positive growth dynamics without critical innovation and economic dependence on the influence of external factors;

2. Maintain an acceptable socio-economic and quality standard of living for the population within the framework of the single economic space of the country;

3. To regulate the economic processes that guarantee sustainable in the framework of the planned annual in-dices of growth of economic results and production efficiency. 
The composition of generalizing indicators of correlation characterizing the medium and long-term development of sectoral and local components, in general, the national economy, their economic security includes

1. economic results (gross value added of products manufactured, services rendered, work performed for the national economy, its structural components; net production, profit for economic entities);

2. the volume of gross value added per capita (for the national economy), by the average annual number of people working in the industry;

3. annual economic result attributable to the average number of personnel of the economic entity;

4. the cost of new and modified types of products and services in the total volume of their production;

5. volume of investments directed to the renewal and modernization of fixed, circulating and human capital.

Medium-term, long-term forecasting of the socio-economic development of business entities and sectoral components of the services sector, which determines the degree of objectivity of economic results, production efficiency and their compliance with economic security, acts as a separate functional element in the planning process, the equivalence of which with other management functions, including planning, is confirmed preparatory, process and final organizational measures, actions on actualization of its functional purpose, to carry out an assessment on the basis of extrapolation of a representative retrospective dynamics of economic performance, the effectiveness of the resources used.

Independence and interaction of the forecasting function with other technological components of the control system manifests itself at such implementation stages as preparatory, process and final. The implementation of these stages of the forecasting process, in accordance with their functional orientation to ensure the adequacy and significance of forecast estimates, the requirements for the accuracy of the medium-term dynamics of changes in economic and social indicators, puts forecasting on a par with such other basic management system functions as regulation, planning, organization, control and accounting $[1,4]$.

The preparatory stage of ensuring the adequacy of forecasting the normative and threshold values of economic security, interaction with other technological elements of the management system of medium and long-term development of business entities, economic activities (sectoral components) of the services sector should contain a set of measures and actions to collect and systematize socio-economic information about the current and retrospective activity of the object of planning and forecasting. At the same time, the preparatory stage of the forecasting process provides an opportunity to form a generalizing extrapolation view of the medium-, long-term development of the local, sectoral component of the service sector on an expert or economic-mathematical basis.

Systematic statistical and other information about the social, economic, innovative development of the object of forecasting in the retrospective period of its activity allows the use of an appropriate forecasting method, the accuracy and practical significance of which in relation to the available past information must meet the requirements of the statistical theory of time series and meet the minimum errors, high degree of accuracy of estimates of the forecast.

At the same time, it should be noted that the adequacy of the medium-term forecast economic assessments of the organization's activities, the sectoral component of the services sector, depends both on the representative number of members of the time series, reflecting trends in economic indicators, and on the forecast method used, its correspondence to the dynamics of quantitative and qualitative changes in economic results, the performance of the selected periods of time forecasting. 
The preparatory stage of the process of medium-, long-term forecasting of the economic and social development of an enterprise and the service industry should facilitate the informative disclosure and concretization of the subsequent stages of ensuring the accuracy and significance of predictive estimates of economic results, costs and efficient use of resources by increasing the level of feasibility of choosing an economic-mathematical or expert method forecast, as well as the comparability of the values of the initial dynamic range in the prices of the basic ode, bringing the value indicators of economic outcomes and costs by discounting the estimated coefficient year.

In order to increase the accuracy and significance of the forecast economic results and the efficiency of the resources used by business entities, the sectoral components of the services sector in the process of solving the set tasks for the planning system to achieve optimal economic results, resource efficiency, in our opinion, it is advisable to make a forecast using various methods for subsequent comparative analysis of the accuracy of the forecast values, in accordance with the requirements of the statistical theory of dynamical series.

It is important to note that the choice of the forecast method mainly depends on the responsibility, experience of the subject of forecasting and planning the medium and longterm development of the socio-economic system. At the same time, participants in the preparatory forecasting period elect a forecasting method, in accordance with which the model is created, and within its framework, the medium-term values of the extrapolation economic development of the business entity are determined, the sectoral component of the services sector.

The process stage of the medium-term forecasting of economic results and the efficiency of resources used connects its origin with the presence of the chosen forecast method, its model, with the goal of subsequently incorporating the generalized volume of retrospective reporting or statistical information about the economic development of the local, sectoral component of the services sector.

\subsection{System of joint interaction summarizing (economic results, indicators of the efficiency of the resources used)}

The forecasting method chosen by the management, a model of mid-term evaluation of economic indicators built on its basis, allows the subjects of planning and forecasting the development of the local, sectoral component of the services sector to obtain the level of forecast accuracy that they can be finally adopted or presented for comparison in terms of accuracy and significance of forecast values obtained by other methods. Ultimately, those projected values of economic results and the efficiency of resources used that have a higher level of accuracy are chosen for practical application.

For example, you can compare the prediction equation obtained by the method of least squares and the forecast model constructed by the method of the average absolute increase and choose the predictive estimates of the model, the forecast error in which is lower compared to another model. At the same time, checking for statistical stability of forecast models should be carried out on the basis of compliance, first of all, with the standard values of the model accuracy parameters and forecast errors, which ultimately determines the level of adequacy of the forecast model to medium-term trends in the development of the forecast object, the possibility of its practical application in the economic planning system results and effectiveness of the service delivery process.

The stage of process medium- and long-term forecasting of economic indicators of business entities and sectoral components of the service sector may also include expert methods of forecasting if data on retrospective changes are not available (for example, for a newly created enterprise). At the same time, experts are highly qualified specialists in the 
field of planning and forecasting the socio-economic development of local and sectoral components of the services sector, based on the existing experience and knowledge gained on the future development of various service delivery processes, on resource potential, determine the quantitative and qualitative characteristics of economic results, costs, generalizing and private indicators of the efficiency of the resources used (for example, return on assets, labor productivity a, material consumption, capital productivity) in the medium and long term $[2,6]$.

The final stage of forecasting the economic results, the levels of efficiency of the resources of the enterprise used, the sectoral components of the services sector begins with the election of a significant and more statistically stable forecast model from several forecast models constructed using various methods.

The predictive model chosen by degree of accuracy should be used in the process of forming plans for socioeconomic development, maintaining the planned dynamics of changes in economic results, and the efficiency of resources used in the current trends in the development of local and sectoral socio-economic systems in the services sector under the influence of negative factors of external and internal environments.

The statistical stability and practical significance of the predictive model of mediumterm assessments of economic results and the efficiency of resources used in a particular socio-economic system of the service sector must satisfy the requirement of the statistical theory of time series, according to which the number of members of the dynamic series exceeds at least twice the number of estimates of the forecast for time periods (on years). When deviating from this condition, forecast errors, characterized by approximation coefficients, can significantly exceed their normative values, which deprives the forecasting model of practical significance when planning a medium-long-term development of a local, sectoral socio-economic system of the services sector.

Failure to comply with the conditions for obtaining statistically stable estimates of the forecast of economic results, costs and effectiveness of resources used in a prospective period of time by business entities and sectoral components of the services sector in the conditions of waiting for changes in the external environment in an established interval or an indefinite time deprives the planning subject of the opportunity to be guided by targets for economic results and the effectiveness of the service delivery process established by forecast methods.

Following this, it should be noted that the obtained values of the forecast of the economic result and the ef-ficiency of the resources used serve as the basis for establishing those planned indicators that, given the economic and innovative changes in the states of the macro- and microenvironment, can be the maximum possible in the medium and longterm periods.

Efficiency and competence of executors in the process of implementation of the forecast cycle stages for obtaining regulatory or threshold values $\mathrm{f}$ economic security based on medium-term assessments of the effectiveness of resources used by the local, sectoral component of the service sector in the presence of reporting or statistical data on activities for a retrospective period of time allow not only to statistically a stable and practical predictive model, but with minimal errors of the effectiveness of the resources used in the medium term.

The adequacy and accuracy of the established medium-term forecast values can be ensured, for example, by such simple economic and mathematical methods as the average absolute growth and the least squares method, in accordance with which the economic and mathematical models of the forecast are compiled and quantitatively interpreted.

Since the establishment of higher accuracy of the predicted economic results of the main sectoral components of the production and services sectors is possible by comparing two or more methods of forecasting the economic results (for example, gross value added) of their 
activities, which, in turn, is one of the adequate characteristics of economic security the studied industries (economic activities) of the service sector, the use of, for example, the least-squares forecast method, It makes it impossible to compare forecast values of an economic result and choose a method for practical use of forecast values, which, according to the statistical theory of time series, largely reflects trends in the members (indicators) of the time series in accordance with the retrospective period of sectoral components' activity $[4,5]$.

However, taking into account the fact that the predicted values of the gross value added of the main industry components of the production and services sectors meet the requirements of the statistical theory of time series and in the medium term correspond to changes in the gross value added of the retrospective period (2010-2018) of time results of the least squares method to past changes of the chosen composition of the members of the dynamic series, in our opinion, will be within acceptable limits of significance compared to the least squares predictive method.

Choosing the gross value added indicator of the studied service components of the service sector as the main identifier of the economic result included in the basic characteristics of the economic security of their activities, in our opinion, should be based on the chosen composition of generalizing measures of the effectiveness of the resources used and the achieved forecast values of the economic result in the medium term form a system of joint interaction summarizing (economic results, indicators of the efficiency of the resources used) and private indicators (the average annual number of employees in the industry, in its small enterprises; the rate of renewal of fixed assets; the use of information and communication technologies in organizations of sectoral components of the services sector; the degree of wear of fixed assets; volume investment indices in fixed capital; turnover small enterprises; investments in fixed assets; average monthly accrued wages of workers in service organizations; use of the Internet in organizations of service industries).

\section{Results}

As an example of the relationship of key macroeconomic indicators, we consider the dependence of a number of investment and lending indicators in Russia. According to a study of a complex of indicators related to investment financing in the Russian economy a number of conclusions can be made, which are presented after the analysis of the Table 1 (Source: calculated and compiled by the authors based on the data of the "Banking Statistics Bulletins", "Reports on the Development of the Banking Sector and Banking Supervision" for the relevant years, as well as data from Rosstat $[6,7,8]$ ).

The table compares the post-crisis 2010 (for Russia, 2009 was characterized by a sharp "failure" of most macroeconomic indicators), as well as the period 2013-2018, which most experts define for the Russian economy as a recession (study period).

The data in the table indicate that during 2013-2016, the index of physical volume of investments in fixed assets decreased, and in 2017-2018 a gradual growth began. The regulation on the state of the recession is clearly characterized by the fact that investments as a percentage of GDP fell from $19.8 \%$ in 2010 to $16.7-17.5 \%$ in $2014-2018$. The value of this indicator for dynamically developing economies (such as China and a number of AsiaPacific countries) is $25-30 \%$, and for industrialized countries - 22-25\% [9].

In 2015 , there was a sharp increase in the cost of financial resources (line of Table 1) to $13.8 \%$, while in other periods this indicator was in the range of $9-11 \%$. It should be noted at the same time that financial resources for many enterprises and individuals are provided at significantly higher rates than the average. At the same time, as an indicator of the average rate, it reflects the huge size of loans received by large companies - the flagships of the economy at minimum rates. 
As a positive trend in the study period, one cannot fail to note a certain increase in the share of long-term loans, which indicates that the financial resources necessary for longterm investments in fixed assets and intangible assets can be transformed from savings within the domestic banking sector.

The key indicator of the economic system in the study period remains the indicator of GDP growth, which demonstrates moderate growth rates of the physical volume of GDP in 201402018 with a "failure" to $-2.5 \%$ in 2015.Authors should use the forms shown in Table 3 in the final reference list.

Table 1. Dynamics of investment and lending indicators in Russia in 2010-2018.

\begin{tabular}{|l|c|c|c|c|c|c|c|}
\hline \multirow{2}{*}{ The name of indicators } & \multicolumn{7}{|c|}{ The value of indicators per years } \\
\cline { 2 - 8 } & 2010 & 2013 & 2014 & 2015 & 2016 & 2017 & 2018 \\
\hline $\begin{array}{l}\text { 1. The level of bank interest } \\
\text { rate (\%) }\end{array}$ & 10,8 & 9,4 & 11,1 & 13,8 & 11,8 & 9,4 & 9,0 \\
\hline $\begin{array}{l}\text { 2. The volume of loans } \\
\text { granted to legal entities and } \\
\text { individuals - residents, in } \\
\text { relation to GDP (\%) }\end{array}$ & 39,2 & 44,4 & 51,6 & 52,7 & 47,5 & 46,0 & 46,1 \\
\hline $\begin{array}{l}\text { 3. Long-term loans (over 3 } \\
\text { years) in the total volume of } \\
\text { loans to the non-financial } \\
\text { sector (\%); }\end{array}$ & 36,1 & 40,5 & 44,3 & 46,2 & 46,1 & 44,0 & 44,9 \\
\hline $\begin{array}{l}\text { 4. GDP at market prices, } \\
\text { billion rubles. }\end{array}$ & 46 & 71 & 79 & 83 & 86 & 92 & 103 \\
\hline $\begin{array}{l}\text { 5. Volume index (GDP } \\
\text { growth rate)\% }\end{array}$ & 104,5 & 101,3 & 100,7 & 97,5 & 100,3 & 101,6 & 102,3 \\
\hline $\begin{array}{l}\text { 6. The share of investment in } \\
\text { fixed assets in GDP,\% } \\
\text { (calculation) }\end{array}$ & 19,76 & 18,94 & 17,55 & 16,67 & 17,12 & 17,41 & 16,98 \\
\hline $\begin{array}{l}\text { 7. Dynamics of the physical } \\
\text { volume of investments in } \\
\text { fixed assets (in\% to the } \\
\text { previous year) }\end{array}$ & 6,30 & $-0,20$ & $-1,50$ & - & $-0,20$ & 4,80 & 4,30 \\
\hline
\end{tabular}

\section{Conclusion}

Purposeful interaction of generalizing and particular indicators is possible in multifactor regression systems, which determine not only the quantitative interdependence of all factors (factor functions and factor-arguments) included in the system, but also their combined ability to reflect the medium and long-term development of the objects of study services) in combination with the observance of the planned (normative) level of economic security and its threshold values $[4,10,11]$.

Ensuring the objectivity of such a declared definition of the functional purpose of a multifactorial linear or power regression system of economic indicators, such as "to establish quantitative mutual influences of factor arguments and factor functions, to determine the predicted values of the factor function when substituting the predicted values of private identifiers into the regression system", its target orientation ("the achievement of the planned results, the effectiveness of the activities of the sectoral components of the services sector on the basis of taking into account the influence of the main economic, organizational and innovative factors on them in a regressive multi-factor system under 
conditions of an unstable state of the external environment") determine the systemic unity of the main, generalized and particular measures of the effectiveness of its activity and economic security at a particular stage (normal, pre-crisis, crisis critical safety status).

\section{References}

1. N.I. Yevmenova, E.N. Krolivetskiy Peter. Econ. J. 1, 97-102 (2019)

2. E.N. Krolivetskiy Pol. Sci. J. 2019 5, 41-43 (2019)

3. V.E. Krolivetskaya J. Leg. Econ. Stud. 1, 22-26. (2017)

4. S.G. Arbuzov Creat. Econ. 10, 10-16. (2016)

5. O.M. Kustov News St. Peter. St. Un. Econ. 4, 155-158. (2016)

6. Bank of Russia. Reports on the Development of the Banking Sector and Banking Supervision, https://www.cbr.ru/publ/nadzor

7. Bank of Russia. Banking Statistics Bulletins, http://www.cbr.ru/publ/?PrtId=bbs

8. Russian Statistical Bureau. Russia in Figures 2013-2019. - URL: http://www.gks.ru/wps/wcm/connect/rosstat_main/rosstat/ru/statistics/publications/cata log/doc_1135075100641

9. V.E Krolivetskaya Monetary conditions of economic growth: theory and practice (2015)

10. D. Radushinsky, E. Markovskaya, V. Holodkova,O. Feoktistova, A. Borisova MATEC Web of Conferences Ser. "International Science Conference SPbWOSCE-2017 "Business Technologies for Sustainable Urban Development" (2018)

11. D. A. Radushinsky, Ye. I. Markovskaya Mon. Cred. 10, 33-39 (2017) 